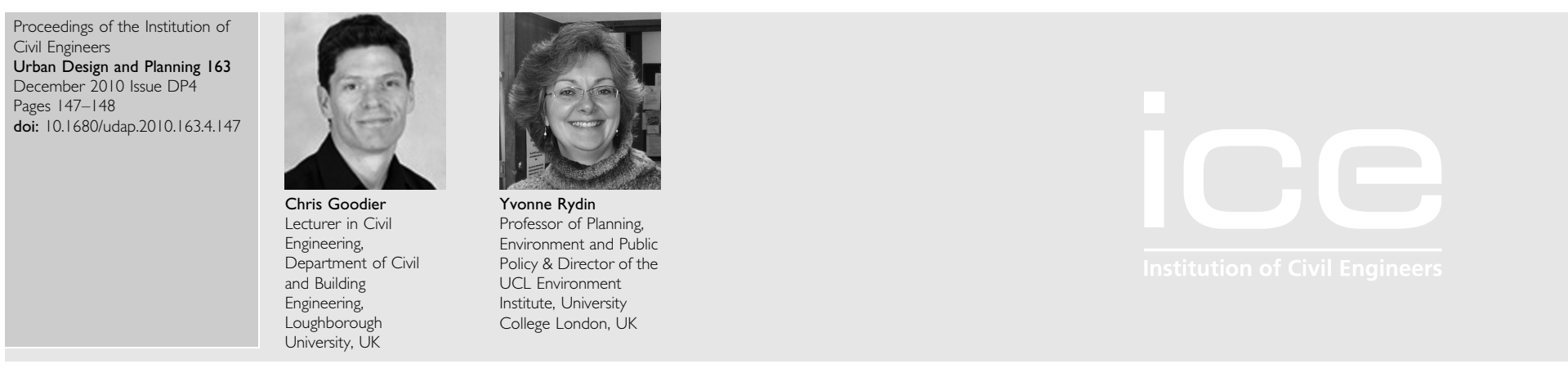

\title{
Editorial: Sustainable energy and sustainable cities
}

C. Goodier PhD, MCIOB, MICT and Y. Rydin PhD, MRICS

Meeting the carbon reduction commitments of the Kyoto protocol alone will make significant demands on our energy systems. Any meaningful replacement for this protocol will make these demands even more stringent. This will particularly impact on cities and other urban areas, both because of the majority of the population living in such areas and the increasing urbanisation of societies and populations. To help meet these challenges, there is globally an increased interest and investment in renewable energy sources, as well as a shift from centralised to more decentralised energy generation and distribution. These changes will have major impacts on how our cities and urban areas in the coming decades are designed, planned, constructed and operated.

Furthermore, there is a role for positive action at the city scale and for action focussed on the built environment in addressing this overall sustainable energy agenda. This admittedly global agenda cannot simply be solved by international action. Even if an agreement had been forthcoming at Copenhagen in December 2009, it would have had to be implemented at national, regional and eventually local level. And, as we saw, such international agreements cannot be relied upon. Yet action on combating climate change by altering the ways we generate, distribute and use energy remains possible at the urban scale. Such alterations can also make a considerable difference: about half of all the energy consumed occurs within buildings through heating, cooling and use of appliances. If one adds the energy used in travel between buildings and across the built environment then the figures rises to nearer three-quarters.

The scale of this challenge means that it can only be met if it is addressed from both a supply and a demand perspective supply in terms of increased use of renewable energy and less reliance on fossil fuels, and demand in terms of stemming (and ultimately reducing) people's and cities' increasing dependence on energy consumption of all kinds. Only when the energy supplies and systems that our urban areas rely on come from renewable sources, and this energy is used as efficiently and as sparingly as possible, will these towns and cities even begin to be thought of as sustainable. By changing the nature of our built environment, how energy supply is integrated into the urban fabric and how we collectively use energy, we can make a significant contribution to action on climate change and hence generate more sustainable cities. The papers in this special issue make this point very clearly.
In order to make progress in reducing energy consumption and hence develop a more sustainable built environment, it helps to be able to measure where you are starting from. The Royal Institution of Chartered Surveyors (Rics) in the UK has therefore recently developed a new index which will provide a different view of how the property sector contributes to the sustainable progress of a country. The whole rationale for this new index was that countries are varying in how they address the sustainability agenda through built environment policies and practices. The paper by Rydin et al. (2010a) presents the results of this index - in which Norway comes top - but also outlines the process of developing an index that concentrates on the role of the built environment in carbon reduction and the dilemmas involved.

Continuing this international perspective, Piercy et al. (2010) discuss Cuba as a case study for reducing a country's reliance on imported fossil fuels after the collapse of the Soviet Union in 1989 decimated the country's imports of energy, food, and other vital supplies. In response to this, or in spite of this, the country has seen itself rise up several international sustainabilityoriented indexes, including the human development index and the happiness index. Numerous lessons exist on how countries can move successfully (though not always painlessly) towards more sustainable cities, societies and economies. The need to radically rethink how energy was used in Havana and Cuba shows the possibilities of creating new sustainable forms of urban lifestyle.

This abrupt and externally-imposed change in reliance on fossil fuels seems extreme when compared with Norway's experiment in using hydrogen as a fuel for transportation, but Kårstein (2010) argues that similar socio-technical synchronisation related to very extensive and complex socio-technical networks may turn out to represent the main challenge when it comes to developing a society based upon renewable energy such as hydrogen. We must learn successfully from projects such as the Norwegian HyNor if we are ever to make that transition.

Socio-technical networks are a recurring theme in many different projects and countries, as well as many of the papers in this issue. The UK and Spain are two further examples of countries implementing similar strategies to try and reorient their cities' energy trajectories onto more sustainable pathways. Maassen (2010) looks at the scope for developing urban level 
energy policies that shape the way in which new urban development occurs and the form it takes. She illustrates this through case studies of London and Barcelona and argues that urban energy infrastructures are thoroughly socio-technical in their emergence, development and use, and that 'municipal climate policy is contested terrain'.

Reducing demand for fossil fuels is of course not just about increasing the use of renewable energy, but about reducing the demand for energy of any kind. With the built environment being the largest consumer of energy and the largest emitter of carbon dioxide it has a significant role to play, and the final papers in this issue by Rice (2010) and Power (2010) argue for the importance of a programme of retrofitting of the existing built environment, with Rice focussing specifically on the suburbs. Both authors discuss how to increase sustainability and energy efficiency by retrofitting existing urban areas, together with the related debate regarding demolition versus refurbishment. However, even this debate becomes social-technical in nature as existing communities argue against the demolition of their poorly-performing homes and other communities argue against energy-efficient new-build developments in neighbouring areas.

This socio-technical synchronisation, combined with decentralised energy and sustainable cities are issues that will be investigated in the new EPSRC-funded research project challenging lock-in in urban energy systems (or Clues), which is introduced in the first briefing by Rydin et al. (2010b). This project will be the first to assess critically the pursuit of decentralised energy systems in urban areas in the light of the need to achieve national decarbonisation goals to 2050 and broader urban sustainability goals. It will focus on the scope for and the implications of scaling up the many individual instances of decentralised urban energy projects and on understanding how the greater emphasis on such decentralisation will reshape our urban environments over the next few decades.

Although an environmental focus in design is now commonplace, Yeang (2010) argues that 'green design' ought to do more and should aim to try and integrate all human interventions in the environment in a seamless and benign way. In the second briefing he argues that green design should go beyond conventional rating systems such as Leed and Breeam because, while being useful for providing a common basis for comparing the environmental credentials of buildings, they are not totally effective design tools and are not comprehensive enough in approaching environmental design issues at local, regional and global levels. He therefore proposes five strategies towards this end, including 'eco-infrastructures', 'bio-integration' and 'eco-mimesis'.

\section{REFERENCES}

Kårstein A (2010) Stumbling blocks on the Hydrogen road in Norway. Proceedings of the Institution of Civil Engineers, Urban Design and Planning 163(4): 177-183, doi: 10.1680/ udap.2010.163.4.177.

Maassen A (2010) Planning urban energy trajectories: London and Barcelona. Proceedings of the Institution of Civil Engineers, Urban Design and Planning 163(4): 185-192, doi: 10.1680/udap.2010.163.4.185.

Piercy E, Granger R and Goodier C (2010) Planning for peak oil: learning from Cuba's 'special period'. Proceedings of the Institution of Civil Engineers, Urban Design and Planning 163(4): 169-176, doi: 10.1680/udap.2010.163.4.169.

Power A (2010) Housing and sustainability: demolition or refurbishment? Proceedings of the Institution of Civil Engineers, Urban Design and Planning 163(4): 205-216, doi: 10.1680/udap.2010.163.4.205.

Rice L (2010) Retrofitting suburbia: is the compact city feasible? Proceedings of the Institution of Civil Engineers, Urban Design and Planning 163(4): 193-204, doi: 10.1680/ udap.2010.163.4.193.

Rydin Y, Maguire S and Austin P (2010a) Dilemmas in developing a sustainable built environment index. Proceedings of the Institution of Civil Engineers, Urban Design and Planning 163(4): 159-168, doi: 10.1680/ udap.2010.163.4.159.

Rydin Y et al. (2010b) Briefing: Challenging lock-in through urban energy systems. Proceedings of the Institution of Civil Engineers, Urban Design and Planning 163(4): 149-151, doi: 10.1680/udap.2010.163.4.149.

Yeang K (2010) Briefing: Strategies for designing a green built environment. Proceedings of the Institution of Civil Engineers, Urban Design and Planning 163(4): 153-158, doi: 10.1680/udap.2010.163.4.153. 